\title{
Product architecture assessment: a tool to link product, process, and supply chain design decisions
}

\author{
Sebastian K. Fixson* \\ University of Michigan, Industrial and Operations Engineering, 1205 Beal Avenue, IOE 2793, Ann Arbor, MI 48109, USA
}

Received 5 August 2003; received in revised form 31 March 2004; accepted 26 August 2004

Available online 30 November 2004

\begin{abstract}
Increasingly heterogeneous markets, together with shorter product life cycles, are forcing many companies to simultaneously compete in the three domains of product, process, and supply chain. Dependencies among decisions across these domains make this competitive situation very complex. To address this complexity, three-dimensional concurrent engineering (3D-CE) has been suggested ([Fine, C.H., 1998. Clockspeed-Winning Industry Control in the Age of Temporary Advantage. Perseus Books, Reading, MA.]). Applying 3D-CE requires an operationalization of one of its core elements: the product architecture. In this paper, I develop a multi-dimensional framework that enables comprehensive product architecture assessments. The framework builds on existing product characteristic concepts such as component commonality, product platforms, and product modularity. The framework's utility is illustrated with two example products, showing how individual product architecture dimensions link decisions across different domains. This framework can be used to focus advice for product design on product architecture dimensions that are critical for a given operational strategy, to assess advantages and limitations of operational strategies in conjunction with given product architectures, or to develop dynamic capabilities such as planning effective product-operation strategy combinations.

(C) 2004 Elsevier B.V. All rights reserved.
\end{abstract}

Keywords: Product architecture; Modularity; 3D-CE; Product-process-supply chain design

\section{Introduction}

For many manufacturing firms, heightened competition throughout 1980s and 1990s has brought back into focus the value of considering manufacturing concerns during product design, and to overlap formerly sequential design processes. Concurrent

\footnotetext{
* Tel.: +1 734615 7259; fax: +1 7347643451 .

E-mail address: fixson@umich.edu.
}

engineering (CE), also called simultaneous engineering, experienced a steep growth in interest from both industry and academia (Fleischer and Liker, 1997; Nevins and Whitney, 1989). Over the last two decades numerous facets of this approach have been researched, ranging from design's impact on ease of manufacturing and assembly processes (Boothroyd et al., 2002; Rusinko, 1999; Whitney, 1988), to the implications for development lead time due to concurrent development processes (Haddad, 1996; 
Koufteros et al., 2001; Roemer et al., 2000; Terwiesch et al., 2002).

More recently, the competition has intensified for many firms through increased demand heterogeneity and shorter product life cycles. Formerly large mass markets have fractured into smaller niche markets demanding higher levels of product variety while competitors are introducing new products in shorter intervals. To respond to these pressures, many firms have put customization of mass produced products at the center of their attention. This development can be observed for products ranging from sneakers with the customer's own name imprinted on them to customized beauty products to personalized food where, for example, each customer picks the ingredients for his cereal (Mirapaul, 2001). Similarly, the automobile market shows increasing numbers of niches, as well as increasing numbers of models in these niches, e.g., sports cars (The Economist Intelligence Unit, 2000a, 2000b). Furthermore, in addition to quality, variety, and price, many products compete today on their level of availability. Firms, such as computer maker Dell, have built their entire business model initially not on superior products but on customization and delivery speed (Magretta, 1998).

For the idea of concurrent engineering, these developments imply the need to enlarge its scope and add supply chain considerations to the tasks to be concurrently addressed. Fine (1998) named this expansion "three-dimensional concurrent engineering (3D-CE)". He argues that all three domains (product, process, and supply chain) possess an architecture, and matching these architectures is key to the success of 3D-CE. Others have introduced the term "concurrent enterprising" to describe the future direction of mass customization (Jiao et al., 2004). They describe it as "an approach to achieving an alliance of customers, products, processes, and logistics by means of parallelity, integration, standardization, teamwork, and many others, for delivering an increasing product variety to satisfy diverse customer needs while maintaining near mass production efficiency" (Jiao et al., 2004, p. 83). While these ideas are conceptually very powerful, relatively little is known about how to actually coordinate the many decisions across the three domains of product, process, and supply chain. This paper argues that the product architecture, when properly defined and articulated, can serve as such a coordination mechanism. Given that various individual product characteristics have been identified as having consequences - enabling or constraining - for individual decisions in individual product life cycle phases, it is argued that a comprehensive product architecture assessment methodology can serve as the nexus to link these decisions with each other.

The remainder of the paper is organized as follows. The next section, starting with a working definition of product architecture, presents two overviews. The first discusses how individual product characteristics can affect various decisions in each of the domains of product, process, and supply chain; the second presents three categories of product architecture modeling and description approaches that exist in the literature. Building on this foundation, Section three develops a multi-dimensional product architecture assessment framework for assembled hardware products, and Section four illustrates the framework's coordination role with two example applications. Section five presents insights on how the framework can improve managerial decision-making, and concludes with providing avenues for future research.

\section{Product architecture: nominal definition and utility in coordinating product, process, and supply chain decisions}

\subsection{Nominal definition of product architecture}

Ulrich defines the product architecture as "the scheme by which the function of a product is allocated to physical components" (Ulrich, 1995, p. 419). With complex mechanical and electromechanical products (automobiles, appliances, etc.), which usually consist of a substantial number of components, the product architecture encompasses the information on how many components the product consist of, how these components work together, how they are built and assembled, how they are used, and how they are disassembled. As such, the product architecture serves the purpose of defining "... the basic physical building blocks of the product in terms of what they do and what their interfaces are to the rest of the device" (Ulrich and Eppinger, 2000, p. 182). To summarize, the product architecture can be nominally defined as a comprehensive description of a bundle of 
product characteristics, including number and type of components, and number and type of interfaces between those components, and, as such, represents the fundamental structure of the product.

\subsection{Some effects of product architecture characteristics on product design, process design, and supply chain design decisions}

To move a product from the initial idea to its arrival at the customer requires many decisions on design and operation of numerous processes in the three domains of product, process, and supply chain. These decisions are of strategic and operational nature, and many of these decisions are constrained, or enabled, by product characteristics such as the number and complexity of components, component commonality, or product modularity (Fig. 1).

In the product (development) domain, decisions with rather long-term horizons range from capability development of design engineers to the selection of locations for development facilities to the formation of strategic development alliances. On the project level, product related decisions comprise questions of product functionality, product line variety, material choices, and product styling (Pahl and Beitz, 1996). Organizational decisions include the number and size of project teams, whether these teams are crossfunctional, methods to steer team group processes, and tools to plan product development milestones, sequences, and the degree of overlap (Brown and Eisenhardt, 1995). Individual product characteristics have been found to affect many of these decisions. The number, size, and composition of project teams, for example, are in most cases not independent of the number, size, and composition of the product's components. It has been found that the organizational structures of product development units tend to mirror the product structures of the products they develop (Gulati and Eppinger, 1996; von Hippel, 1990). This phenomenon has been identified as beneficial in stable industries (Sanchez and Mahoney, 1996) and detrimental in dynamic industries (Chesbrough and Kusunoki, 1999; Henderson and Clark, 1990). In either case, the structure that is initially selected for the product will affect the task structure of the product development organization, and the task structure, in turn, contributes to the organization's performance
(Eppinger et al., 1994). The underlying reason is that the task structure determines the interaction and communication patterns of the development teams. For example, high levels of product complexity are usually detrimental to fast product development because they translate into complex process interactions which in turn increases the number of iterations in the development process (Ahmadi et al., 2001; Terwiesch et al., 2002). Reducing product complexity, for instance by regrouping components into fewer modules, has been identified as a way to shorten product development time (Griffin, 1997). For multiple projects, both development cost and time can be lowered if components can be reused across product families (Clark and Fujimoto, 1991; Nobeoka and Cusumano, 1995; Reinertsen, 1997). Similarly, the extent to which decision makers in product development can choose to overlap the development activities is influenced by the degree to which the relations between the components hinder or promote the reduction of process iterations. For example, lowering the degree of interaction between components has been found to positively affect development time (Loch et al., 2003; Thomke, 1997; Yassine et al., 2003).

Decisions on the strategic level in the process domain typically affect large-scale production investments; examples for these decisions are the size of production capacity, the type of manufacturing processes, or the locations of production facilities. On the tactical level, examples of relevant decisions include the scheduling of production, the organization of teams, and the planning of maintenance. A major class of decisions in the process domain is the selection of number and type of processes that will be used to manufacture the product. These decisions are not independent of product architecture characteristics such as complexity of the individual components, number of components, extent to which components can be reused across product families, or degree of coupling between components. High levels of part complexity, for example, have been found to require complex manufacturing processes which result in relatively higher production costs compared to simpler parts that require simpler processes (Banker et al., 1990). For this reason, design for manufacturability (DFM) calls for part simplification, which allow process simplification that results in higher yields and 


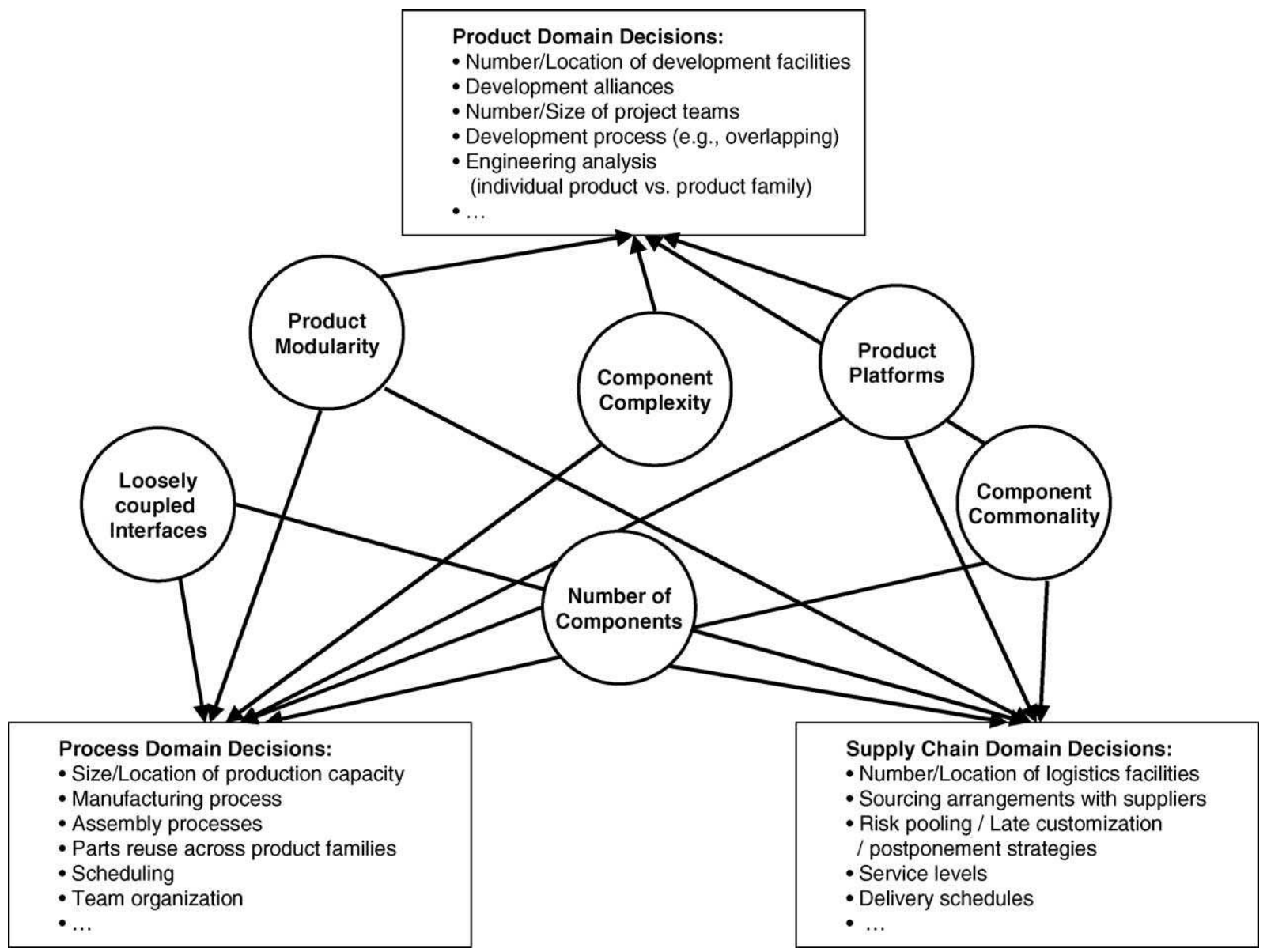

Fig. 1. Product characteristics impacting (constraining and enabling) design decisions in product, process, and supply chain domain.

lower costs. At the same time, part count has been identified as a major cost driver in assembly (Boer and Logendran, 1999). The explanation for this effect is simple: fewer parts require fewer assembly operations, which saves time and cost. Consequently, design for assembly (DFA) aims for part count reduction (Boothroyd et al., 2002). The total cost effect of product characteristics proposed by DFM and DFA depends on the specific circumstances. For example, for cellular network base stations, it has been found that a reduction of the number of physical modules has led to a reduction in operation (manufacturing) costs (Kaski and Heikkila, 2002). If components can be reused across product families or multiple product generations (commonality), scale effects can reduce the cost per unit by distributing the fixed cost portions across larger volumes. This effect has been identified for mopeds, custom-phones, and microwave ovens (Salvador et al., 2002). The magnitude of these savings, however, needs to be compared to the cost for potential 'overdesign' of the component for some of the products in the product family. Products whose production costs are dominated by variable materials costs, such as automotive wire harnesses, may not gain much through the use of commonality (Thonemann and Brandeau, 2000).

Interfaces between components that are only loosely coupled tend to minimize complexity and uncertainty within the production process. Hence, the better the process is known and the more likely it can be performed successfully, and the lower the total number of different processes in the production system is, the lower the expected production costs. For example, electronic interfaces that consist only of 
a plug and a socket may be easier to assemble errorfree than a complex mechanical rod connection. In addition, the testability of pre-assembled units, and their costs, can be affected by the interfaces between them.

In the supply chain domain, decisions of strategic nature include number and location of logistics facilities, contractual relations with suppliers, longterm sourcing arrangements, and postponement and mass customization strategies. Examples for operational decisions relate to service levels, delivery schedules (e.g., just-in-time), vehicle routing, and crew planning. Individual product architecture characteristics that have been identified to affect these decisions are the degree of commonality across components, the way in which the components interact with each other, and the type of the interfaces between the components. For example, the decisions on number and location of suppliers, on the service level, and on delivery frequencies are all impacted by the number and type of components a product consists of. The use of common components allows inventory levels to be lowered through risk pooling (Baker et al., 1986; Collier, 1982; Gerchak et al., 1988). To take advantage of this effect requires an understanding of which function of a product will be provided by which component and the development of an allocation plan. The goal to increase a supplier's incentive to deliver high quality components can be supported by designing components whose functions can be traced individually in the end-product (Baiman et al., 2001). However, the independence of components can also result in shifts of bargaining power between supply chain partners and thus change their competitive positions (Doran, 2003; van Hoek and Weken, 1998). Depending on the industry, the level of component independence can also affect a firm's sourcing strategy: outsourcing commodity items and keeping components of strategic relevance in-house (Momme et al., 2000).

The type of interfaces between components can affect the extent to which strategies for postponement and late customization can be realized. Maximizing the benefits from a postponement strategy may require a re-sequencing of processes (Feitzinger and Lee, 1997; Lee and Tang, 1998). However, some interface qualities together with some manufacturing processes may make an operation reversal impossible. For example, if a metal welding process is used after paint is applied to the product, the welding is likely to destroy the paint.

\subsection{Product architecture models and descriptions in the literature}

To analyze the many effects that individual product architecture characteristics exert on different decisions across the domains of product, process, and supply chain, a variety of different models and descriptions have been developed. Without claiming exhaustive representation, I organize below the existing models into three categories and present their advantages and limitations.

The first category can be labeled mathematical models. These models often simplify the product architecture in order to be able to focus on the effect of interest. For example, to explore the advantages and disadvantages of platform-based product development, each product of a product family is assumed to consist of a common component, i.e. the platform, and a product-specific component (Krishnan and Gupta, 2001). The core of this model analyzes the effects of this choice compared to two independent products, given different degrees of market diversity and nonplatform economies of scale. Similarly, modeling the quality impact of function traceability, Baiman et al. (2001) distinguish between only two cases: one where component and functions are in a one-to-one relationship (decoupled) and one where they are not (coupled). Other models incorporate a larger number of components and focus on the effects of the interactions among them on product development by assigning probabilities for rework due to overlapping processes (Ahmadi et al., 2001). The optimization model's objective then is to minimize the time consumed by the iterations. In fact, a variety of optimization models have been developed to optimize the platform choice, either following a module-based strategy or a scale-based strategy (Simpson, 2003). Most of these models view the product family design problem as optimizing the tradeoff between commonality and distinctiveness (Desai et al., 2001; Krishnan and Gupta, 2001), while some pursue an optimization of the supply chain by rearranging process sequences (Garg, 1999). The advantage of these mathematical models is their computational elegance as well as their 
broad applicability (across industries and across products). At the same time, however, their generic nature makes it often difficult to translate the findings into specific advice for the product architecture design.

Models in the second category, which I call conceptual models, are strongly influenced by research work on product modularity. This category can be further separated into two subsets. Work in the first subset is based on the description of product modularity by Ulrich and Tung (1991). Ulrich and Tung described five different types of modularity: component-swapping, component-sharing, fabricateto-fit, bus, and sectional. Ulrich later collapsed the first three types into one and called it slot architecture (Ulrich, 1995; Ulrich and Eppinger, 2000). Others have subsequently renamed the fabricate-to-fit as cutto-fit and added mix modularity, the latter to include processed products (Pine, 1993). More recently, Salvador et al. (2002) added combinatorial modularity as a specific form of slot modularity. The second subset in this category focuses more on understanding the system effects and the characteristics that such a system exhibits, as opposed to providing detailed descriptions of the components. Some authors focus on the effects a modular product can have on the structure of an industry (Langlois and Robertson, 1992) or on a firm's organization (Sanchez and Mahoney, 1996). Others concentrate on a system's ability to accept upgrades and re-use (Garud and Kumaraswamy, 1996), or on the forces that drive a system towards (e.g., demand heterogeneity) or away from (e.g., synergistic specificity) higher levels of modularity (Schilling, 2000). Placing their emphasis on the nature and role of the interfaces, instead of the components, Baldwin and Clark (2000) present in their extensive work the mechanisms by which an architecture changes. They develop six 'operators' to describe the evolution from one product architecture to another: splitting a design into modules, substituting one module for another, augmenting - adding a new module to the design, excluding a module from the design, inverting to create new design rules, and porting a module to another design. While conceptually very powerful, the modularity descriptions in the conceptual category have been difficult to test empirically. A major reason for this problem is that modularity definitions come in different flavors. They range from describing different product architectures by changing a single parameter of a component, to rearranging components into new combinations, to entirely reassigning functions to different components (Fixson, 2003). The few empirical studies that exist measure product modularity indirectly by asking company employees to assess the degree to which their customers can individually change the design (Duray et al., 2000), to estimate the degree to which products 'share common modules' or 'can be reassembled in different forms' (Tu et al., 2004), or to approximate the degree of independence between components in the event of a design change to one of the components (Worren et al., 2002).

The models in the third category fall under engineering models. These models are typically more applied than those of the previous two categories. Most models provide indices to compare product architectures along the dimensions of interest. For example, one model presents two indices, one - the generational variety index - reflecting the amount of redesign effort required for future product generations, the other - the coupling index - indicating the coupling between product components (Martin and Ishii, 2002). The indices are based on qualitative assessments of the speed of technology development and the strength of the linkages between components, respectively. Others have developed indices to assess the compatibility of components in a module with respect to their material (Allen and Carlson-Skalak, 1998; Newcomb et al., 1998), product function (Huang and Kusiak, 1998), or manufacturing processes (Kota et al., 2000). Some of these models employ variations of a design structure matrix (Steward, 1981), which lists in its top row and first column the product's components. Each cell in the matrix then represents a functional interaction between components of the product. Algorithms have been developed to cluster the components by rearranging columns and rows, and to assign the components to modules based on various matching criteria, e.g., material, functionality, etc. Derivatives of the design structure matrix list the design tasks that correspond to the components in the first column and first row (Browning, 2001). Then the cells in the matrix reflect precedence relationships, i.e., which task supplies data to or receives information from which other tasks. These design structure matrix 
versions have been used to study organizational behavior in design organizations (Sosa et al., 2003). In general, engineering models serve their individual purpose very well; however, they are often difficult to transfer due to their application specificity.

\subsection{Requirements for product architecture measures for trade-off analyses}

The brief reviews of some of the effects of individual product architecture characteristics on decisions across the three domains, and of three classes of product architecture descriptions lead to two requirements that a product architecture assessment tool must meet to show the product architecture as a coordinating mechanism. First, since there are numerous linkages between product architecture characteristics and decisions across the three domains, the tool must be able to discern these different linkages. To do so it must capture all relevant dimensions of the product architecture simultaneously, but show them separately. For to allow the identification of an individual product architecture characteristic as a cause, the tool must be able to observe its variation while 'controlling' for the other product architecture dimensions. Second, the product architecture assessment tool must initially keep description separate from evaluation, because a particular product architecture characteristic might positively enable a decision in one domain (e.g. product development) while having a negative constraining effect in another domain (e.g., supply chain). Separate description and evaluation allow for the detection of the cause-consequence relationships in these cases.

\section{Product architecture-an operational definition}

To develop a product architecture description that is comprehensive and at the same time operationalizable, I augment the nominal definition proposed in the previous section with Ulrich's (1995) distinction between modular and integral architectures. "A modular architecture includes a one-to-one mapping from functional elements to physical components of the product, and specifies de-coupled interfaces between components. An integral architecture includes a complex (non one-to-one) mapping from functional elements to physical components and/or coupled interfaces between components" (Ulrich, 1995, p. 422). To demonstrate his typology he uses two trailers with different architectures (Fig. 2).

Ulrich acknowledges that his typology describes ideal types: "The types shown are idealized; most real products exhibit some combination of the characteristics of several types. Products may also exhibit characteristics of different types depending on whether one observes the product at the level of the overall final assembly or at the level of individual piece parts and subassemblies" (Ulrich, 1995, p. 424). In order to achieve the ultimate goal to assess the impact of product architecture decisions on decisions in the domains of product, process, and supply chain, what is needed then is a method to determine where in between these extremes - modular and integral - a particular design is located in the space of possible function-component mappings, or, at a minimum, how two or more mappings compare to each other with respect to their locations in this space. To develop a framework that allows this type of comparative analysis, I expand Ulrich's work in three dimensions. First, for his ideal cases, Ulrich defines jointly how functions are allocated to physical components and whether interfaces are coupled. I will relax this joint requirement. While both dimensions are necessary for a complete description of a product architecture, these two dimensions are, to a large extent, independent from each other and, consequently, should be treated independently. Second, both dimensions, function allocation and interfaces, appear to be themselves multi-dimensional constructs. Therefore, the framework to be developed needs to be capable of capturing all aspects of the multiple underlying dimensions. Third, since the notions of modular or integral are associated with an allocation of the functionality of the product, it appears that a label for the entire product is essentially creating an average assessment of the product architecture. I argue that this average hides too much of the information of interest, and that a finergrained description is necessary. Below I suggest a product architecture assessment framework that satisfies these three expansions of Ulrich's product architecture description. The suggested framework combines the comprehensiveness of the conceptual 


\section{Trailer 1}
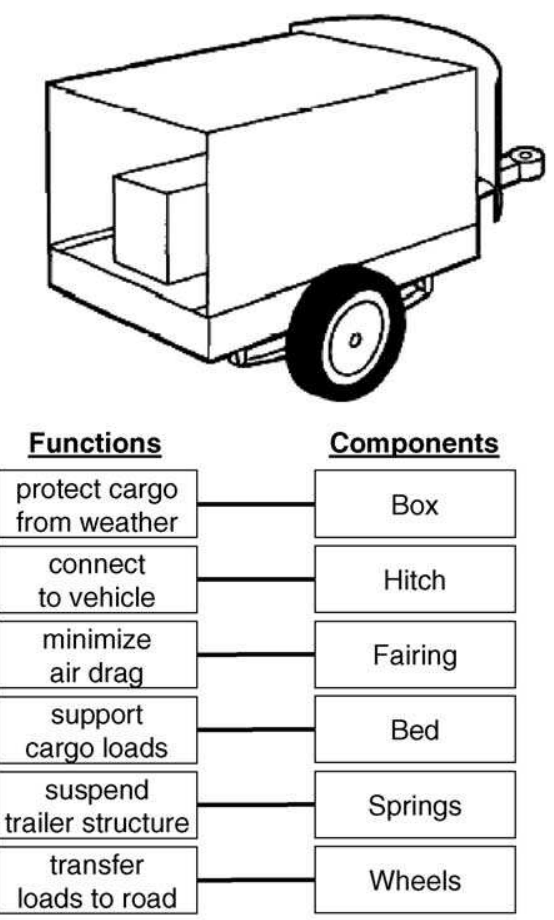

Trailer 2
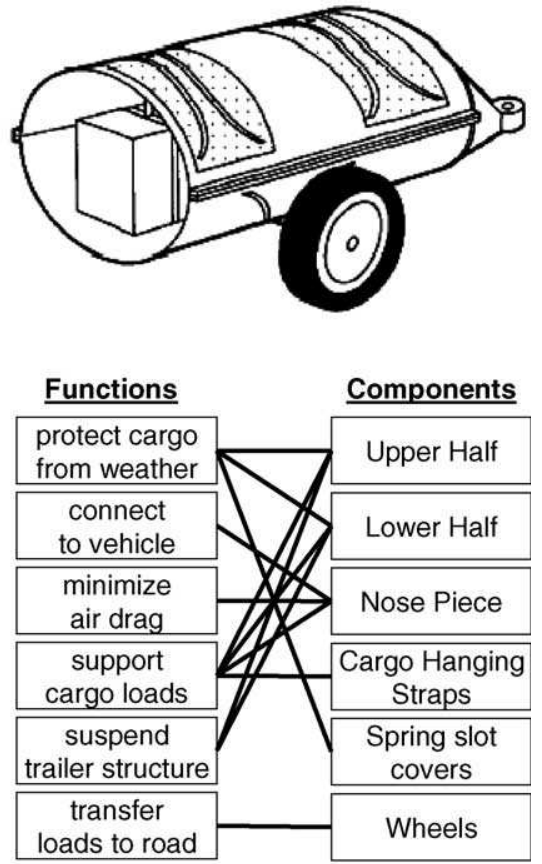

Source: Ulrich (1995) "The role of product architecture in the manufacturing firm"

Fig. 2. Two trailers.

models with the operationalizability of the engineering models and lays the foundation for mathematical models to be applied to individual aspects.

\subsection{Product architecture assessment-dimension 1: function-component allocation scheme}

To build on the definition that a characteristic feature of a product architecture is the way in which functions are allocated to components requires a mechanism that determines and measures this dimension reliably. In other words, all three pieces of the function-component allocation (FCA) scheme need a rule-based procedure to ensure repeatable results: (a) what is a function, (b) what is a component, and (c) how is the allocation scheme established?

\subsubsection{A product's functions}

Two aspects require consideration when determining the functions for product architecture assessment: (i) what are a product's functions and (ii) how can they be determined. What is called function here includes technical functions as well as attributes as would be used by marketing. An example of a technical function is the acceleration of an automobile. For direct comparisons of product architectures across products the function should be provided on a similar performance level. ${ }^{1}$ Examples for attributes that escape technical function descriptions are the color or surface structure of an appliance or the aesthetic appearance of an automobile. Again, for apple-to-

\footnotetext{
${ }^{1}$ Determining functionality sometimes raises the question regarding performance. In some cases the performance is directly measurable and varies along a continuum (e.g., MB per disc area for disc drives). Then further inquiry is needed to determine on what basis to compare products and their architectures. In many other cases, however, the functionality has already passed a certain performance threshold. If the functionality then is perceived more as a binary variable (e.g., there are power windows in a car door or there are not), rather than on a continuum (e.g., how long does it take to open and close the window), then the assumption of equal functionality - at least within a certain range - is a good starting point to compare products and their architectures.
} 
apple comparisons of two or more product architectures the attributes should be provided on a similar level. $^{2}$

The second aspect requires a closer look at the hierarchy level on which a product's functions are selected. Every product's function can be decomposed into sub-functions, and these sub-functions can be decomposed further into lower level sub-functions (Pahl and Beitz, 1996). Two thoughts are suggested to guide the function determination process: comparability and applicability. First, since this framework is developed as a tool to compare products with respect to their differences in their product architectures (i.e., with respect to their different degrees of being modular or non-modular, the function selection should consider choosing a level on which the variance in function-component allocation between the products becomes visible. In its most simple case, this means choosing functions that are in full or to the same degree delivered by the different architecture candidates. Second, the function selection should neither choose the highest level of the functional hierarchy nor the lowest in order to be meaningful. The function on the highest level is necessarily provided by all components, for otherwise there would not be a reason for them to be there at all. For example, assume a hair dryer is the product under investigation. Its main (and highest level) function is 'to dry hair'. If 'to dry hair' were selected as a function of interest, the result would be the allocation of this function to all components, for no component of the hair drier would exist in the first place if it were not contributing to the product's functionality. On the other hand, if the function is chosen too low, e.g., 'hold part A in position $x$ relative to part B with force $f$ ', then exactly one and only one component delivers this function, i.e., the function tends to become idiosyncratic to a particular design. In other words, if the function description is too detailed, i.e., on a very low level of the function hierarchy, it is likely to predetermine its realization with parts and components. In either of these extremes the function-component allocation schemes would be trivial. In contrast, if one begins to

\footnotetext{
${ }^{2}$ The exact performance levels of attributes are typically either hard to determine ("Does a hatchback look 'better' than a sedan?") or are entirely based on individuals' preferences ("Max prefers a red bicycle over a blue one.").
}

define functions like 'generate air flow', 'heat air flow', 'control heat', 'control air flow', and 'supply energy', then it becomes more meaningful to investigate how they are mapped to the components. When in doubt, a level should be chosen that is rather higher than lower in the functional hierarchy because the higher a function is located in the functional hierarchy the closer it is to an actual user need. Users usually care about that a function or attribute is provided, but not necessarily how it is provided by certain technical solutions on lower hierarchy levels.

\subsubsection{A product's components}

Similar to the case of product functions, two aspects drive the product component determination: (i) what is a component and (ii) how is it determined? To maintain maximum flexibility of the product architecture assessment framework, component is used here as a pure placeholder. It is defined here such that it can represent all subsystems, modules, or parts (above connectors such as clips and screws). What the components ultimately represent depends on the second aspect to consider: the selected hierarchy level of the product.

Almost all assembled products simultaneously display some sort of inner hierarchy and are also part of a larger system and its hierarchy. This phenomenon has been described as nested hierarchies (Alexander, 1964; Christensen, 1992; Gulati and Eppinger, 1996; Simon, 1962). Consequently, it is important to determine the product hierarchy level that corresponds to the level of functions determined earlier. Mechanisms that can help in this process are assembly trees or assembly fishbone diagrams (Fig. 3). The source of this information can be a tear-down analysis in which a product is physically disassembled to understand its structure and parts (Ulrich and Pearson, 1998), or design drawings and assembly process descriptions. Working backwards through the assembly tree, starting from the full product, all components (parts, modules, subassemblies, etc.) that are assembled directly to the main component are considered on the relevant level.

\subsubsection{Function-component allocation (FCA) schemes}

To increase product variety, firms mostly vary only some functions or attributes of a product but never all of them. In fact, the basic idea of concepts such as mass customization, product platforms, and common- 
Trailer 1

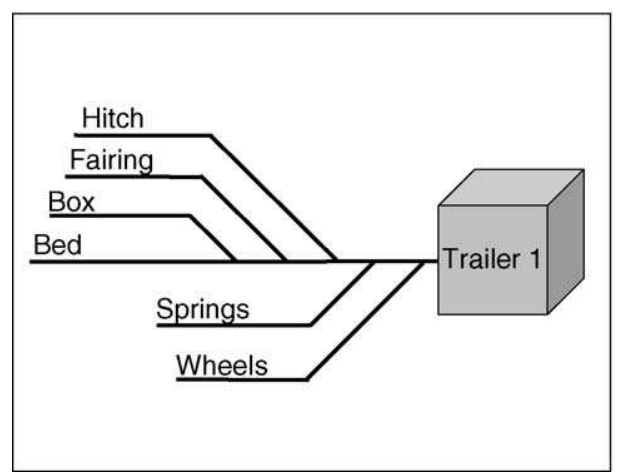

Trailer 2

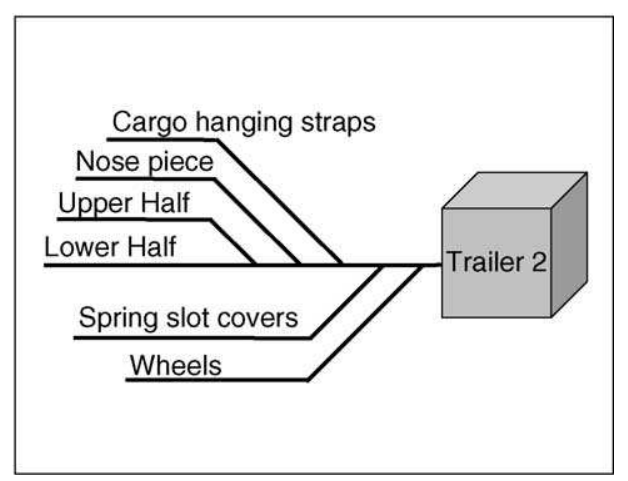

Fig. 3. Assembly fishbone diagrams.

ality, is to reuse some parts of a product across a product family or multiple product generations. What this implies is that the extent to which a product architecture is modular, or non-modular, is information that is required for each function and attribute individually. In addition, how exactly a function is different from the perfectly modular situation, as exemplified by the one-to-one relationship between function and component, is important knowledge because it is the first step to turn the functioncomponent relationship into a design parameter.

Using the product's functions and components as determined in the previous sections, the FCA scheme can be determined and mapped in three steps. The first step is to construct a matrix with the product's functions in the first column and its components in the first row, and to determine which component contributes to which function. In its most simple way a component's contribution to a particular function is indicated in a binary fashion, i.e., yes/no or $1 / 0$. Alternatively, percentages of a function can be allocated to components that contribute to this function. Both approaches have their advantages and disadvantages. For the integer solution, simplicity is its virtue. Whether or not a component plays any role in a function is usually easier to identify than its proportional contribution. In addition, for a number of product planning considerations, it is often sufficient to know which components are involved in providing a certain function or attribute. On the other hand, for some functions and characteristics like size or weight, it may be worthwhile to assess the contribution that is provided by individual components. Fig. 4 illustrates the function-component matrices for the two example trailers using the binary allocation procedure.

Step two in determining the FCA is to calculate two indices for each function that show how each function deviates from the perfectly modular situation, represented by a one-to-one relationship with a component. Possible deviations are $1-n, n-1$, and $n-n$ relationships. The two suggested indices reflect $x$ and $y$ of this $x-y$ relationship. The first index identifies the number of components that jointly provide a function. This index is calculated for each function in the column 'Index 1' (Fig. 4). The second index assesses the extent to which this set of components also contributes to other functions. To calculate that index, I developed a routine that checks for every component that was identified in the Index 1 calculation, the number of functions the component is involved in, and transfers the sum into the last column of the FCA matrix (Index 2). For example, three components of trailer 2 (upper half, lower half, and spring slot covers) contribute to the function 'protect cargo from weather' (Index $1=3$ for this function). Some (or all) of these three components also contribute to the functions of 'support cargo loads' and 'suspend trailer structure' (Index $2=1+2=3$ for the function 'protect cargo from weather').

In step three, these two indices are used to map each function onto the function-component allocation map. The maps are divided into four regions, each representing a FCA style. Every function can be located in one of these four regions. Functions that are located in the lower left region of the map are close to the 'ideal' modular one-to-one relation between function and component. These functions exhibit a 

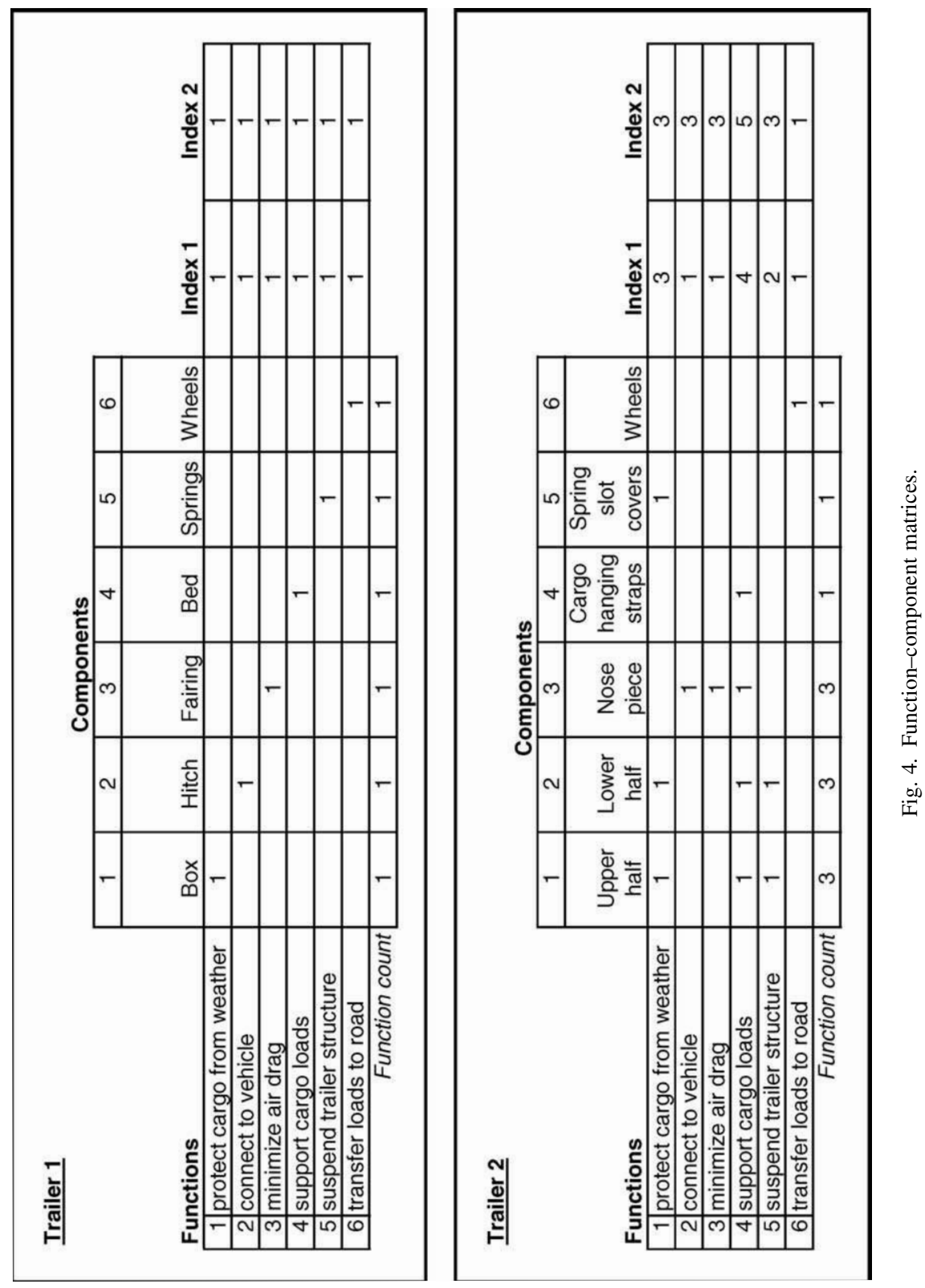


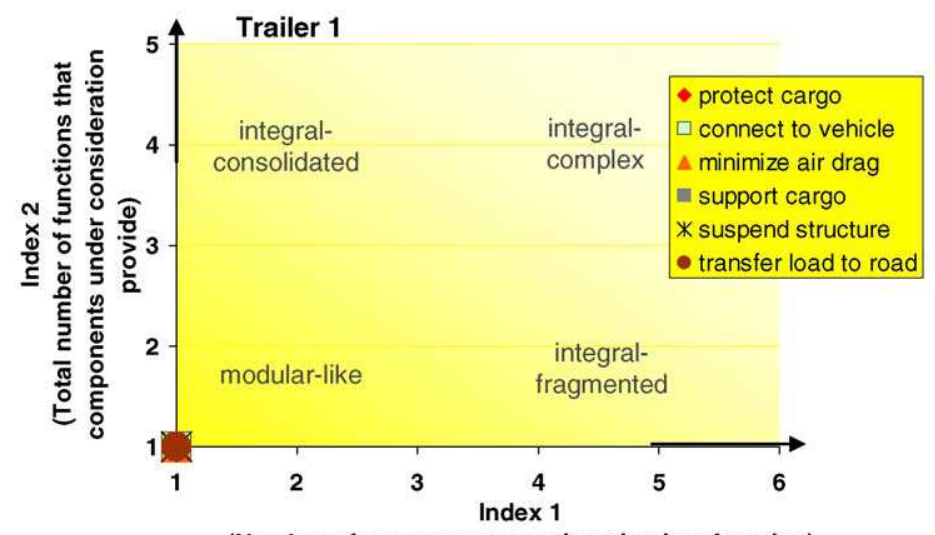

(Number of components particpating in a function)

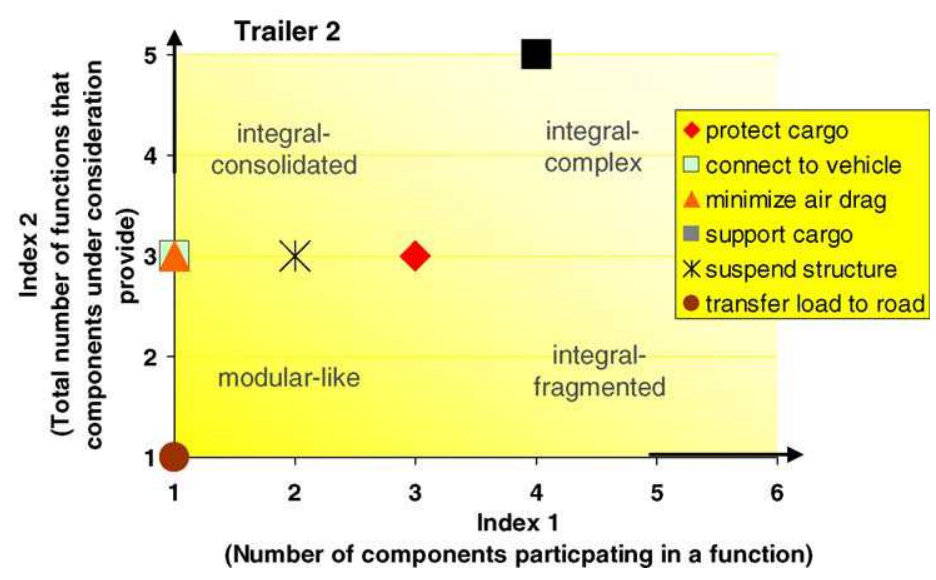

Fig. 5. FCA maps.

modular-like FCA style. If a function is provided by a larger set of components, which individually are not involved in other functions, then the function is located in the lower right region of the FCA map, i.e., it exhibits an integral-fragmented FCA style. In contrast, if one component delivers several functions, these functions will be located in the upper left region of the map, i.e., they show integral-consolidated FCA styles. Finally, only if multiple components provide multiple functions in such a way that most components participate in most functions, then the functions would be located in of the map's upper right region. These functions are of the integral-complex FCA style. Mapping all functions onto FCA-maps makes the pattern of FCA styles of the whole product visible. Fig. 5 shows the FCA maps for the two example trailers. It shows how different architectures differ from each other along individual functions. For example, in the case of trailer 1 , all functions can be found in the lower left corner. All functions exhibit a perfectly modular function-component allocation scheme. In contrast, while trailer 2 has non-modular relations between most functions and components, it does so to varying degrees. The function "transfer load to the road', for instance, is on the same modularity-level as it is for trailer 1. However, the functions 'minimize air drag' and 'connect to vehicle' are entirely and jointly provided by the same component. These functions exhibit an integral-consolidated style. In contrast, the function 'support cargo' exhibits an integral-complex style-being provided by several components that are also involved in providing other functions.

Note that a FCA scheme on one level of the product and function hierarchies says nothing about FCA schemes on other hierarchy levels. For instance, consider a disc drive as part of a personal computer. 
Investigating the role of the disc drive for the FCA scheme of the computer will produce a different result than the analysis of the disc drive's internal FCA scheme. In sum, FCA schemes have to be defined anew for each level of the hierarchy, and one product can have different schemes on different levels. Similarly, different products can have similar FCA schemes on some levels while exhibiting quite different ones on other levels.

\subsection{Product architecture assessment-dimension 2: interface characteristics}

A product's interface characteristics are often described with terms such as 'coupled' or 'dependent' (e.g., Baldwin and Clark, 2000; Schilling, 2000). However, products can exhibit different degrees of being coupled, depending on the product life cycle phase. For example, a coupling with respect to a certain product function may or may not be the same coupling that determines whether a user can easily replace the component providing that function. Consequently, the interface measurement needs to be conducted on a disaggregated level to allow investigation of the individual effects. To make the dimension interface measurable, I group the information into three categories: the interfaces' role for the product function ('type'), their role for making, changing, and unmaking of the product ('reversibility'), and their role with regard to substitutes ('standardization'). In each category, the corresponding interface characteristic is assessed individually. Like the function-component allocation, the interface assessment investigates the characteristics of the interfaces only on the determined hierarchy level.

\subsubsection{Interface type}

The interfaces' roles for the product function, i.e., their types, are determined by their number and distribution across the product, their nature, and their intensity. Obviously, the simple count correlates to some degree with the number of components the product consists of (at the hierarchy level under consideration). If the number of components is $n$, then the number of interfaces is at least $n-1$ and at most $(n(n-1)) / 2$; the former would be a string of components, the latter a web of connections where every component forms an interface with every other component. This rather simple calculation assumes that only one connection or interface exists between two components and abstracts multiple or multidirectional connections into a yes/no relationship.

The distribution of the interfaces provides additional information about the product architecture. For example, if a component interacts with a significant number of other components (relative to the total number of components) there are two possible explanations. First, the component may play a pivotal role in the product architecture. It could signal a central component, one that supplies general or central functionality. This resembles what most researchers understand as a product platform (Meyer and Lehnerd, 1997; Simpson, 2003). Second, the product architecture under consideration may not be very modular, but rather fragmented. A product architecture with fragmented FCA styles is more likely to have many components that show interactions with many other components than a product architecture with modular FCA styles.

Depending on the functionality of the components participating in the interfaces under consideration, the interfaces can also vary in their nature and intensity. The interfaces' 'nature' reflects the physical effects that occur for the interface to play its intended role. For example, an interface can transmit mechanical force, electrical energy, or signals. It can also represent a non-contact relation, e.g., the gap between fender and hood of an automobile, or the signal transmission between a wireless router and a wireless PC card. An interface's 'intensity' reflects its strength and desirability with respect to its functional role, i.e., its nature. To some extent this is a measure of the degree of coupling, albeit for the functional role only. To assess an interface's nature and intensity I build on work by Pimmler and Eppinger (1994), who have developed a methodology for the analysis of product design decomposition. ${ }^{3}$ After decomposing the pro-

\footnotetext{
${ }^{3}$ Pimmler and Eppinger's methodology helps to describe the interactions between components and can be used to guide improvements in design and team organization. In contrast to Pimmler and Eppinger, who propose their methodology to improve the design by rearranging units such that the number of off-diagonal interactions is reduced, the methodology suggested here uses the matrices for descriptive purposes only. This also allows using only the upper half of the matrix. The lower half is reserved for determining the interfaces' levels of reversibility (see next section).
} 


\begin{tabular}{|c|c|c|c|c|c|c|}
\hline & $\begin{array}{l}1 \\
\text { × } \\
\text { ○ }\end{array}$ & 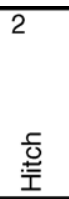 & 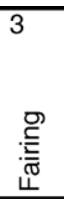 & $\begin{array}{l}4 \\
\text { ఫ্ळ } \\
\varnothing\end{array}$ & $\begin{array}{l}5 \\
\text { 을 } \\
\text { के }\end{array}$ & $\begin{array}{l}6 \\
\frac{0}{\Phi} \\
\stackrel{\infty}{3} \\
\stackrel{5}{3}\end{array}$ \\
\hline 1 Box & & $\begin{array}{ll}2 & 1 \\
1 & 0 \\
\end{array}$ & & $\begin{array}{ll}2 & 0 \\
0 & 0 \\
\end{array}$ & & \\
\hline 2 Hitch & $\begin{array}{l}3 \\
1 \\
\end{array}$ & & $\begin{array}{ll}2 & 0 \\
0 & 0 \\
\end{array}$ & & & \\
\hline 3 Fairing & & $\begin{array}{l}2 \\
1\end{array}$ & & & & \\
\hline $4 \mathrm{Bed}$ & $\begin{array}{l}2 \\
1\end{array}$ & & & & $\begin{array}{ll}2 & 0 \\
0 & 0\end{array}$ & \\
\hline 5 Spring & & & & $\begin{array}{l}2 \\
2 \\
\end{array}$ & & $\begin{array}{ll}2 & 0 \\
0 & 0 \\
\end{array}$ \\
\hline 6 Wheels & & & & & $\begin{array}{l}2 \\
2 \\
\end{array}$ & \\
\hline
\end{tabular}

REVERSIBILITY of Interfaces (lower triangle)

\begin{tabular}{r|l|} 
Effort 1 \\
Depth 1 \\
\hline
\end{tabular}

Effort to reverse Depth in which interface is located easy $1 \quad$ shallow 1

medium 2 medium 2

difficult $3 \quad$ deep 3

\begin{tabular}{|c|c|c|c|c|c|c|}
\hline & $\begin{array}{l}1 \\
\frac{+}{\widetilde{T}} \\
\frac{1}{1} \\
\bar{\Phi} \\
\stackrel{0}{2} \\
\end{array}$ & 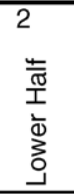 & 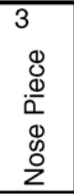 & 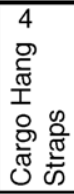 & 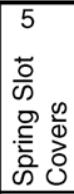 & $\begin{array}{l}6 \\
\frac{\infty}{\Phi} \\
\Phi \\
\frac{\Phi}{3}\end{array}$ \\
\hline $\begin{array}{l}1 \text { Upper } \\
\text { Half }\end{array}$ & & $\begin{array}{ll}2 & 0 \\
0 & 0\end{array}$ & $\begin{array}{ll}2 & 0 \\
0 & 0\end{array}$ & $\begin{array}{ll}2 & 0 \\
0 & 0\end{array}$ & $\begin{array}{ll}2 & 0 \\
0 & 0\end{array}$ & \\
\hline 2 Lower Half & $\begin{array}{l}2 \\
2\end{array}$ & & $\begin{array}{ll}2 & 1 \\
1 & 0 \\
\end{array}$ & & & $\begin{array}{ll}2 & 0 \\
0 & 0 \\
\end{array}$ \\
\hline $\begin{array}{r}3 \text { Nose } \\
\text { Piece }\end{array}$ & $\begin{array}{l}2 \\
1\end{array}$ & $\begin{array}{l}2 \\
1\end{array}$ & & & & \\
\hline $\begin{array}{c}4 \text { Cargo } \\
\text { Hang }\end{array}$ & $\begin{array}{l}1 \\
1\end{array}$ & & & & & \\
\hline $\begin{array}{l}5 \text { Spring } \\
\text { Slot }\end{array}$ & $\begin{array}{l}2 \\
2 \\
\end{array}$ & & & & & \\
\hline 6 Wheels & & $\begin{array}{l}2 \\
2 \\
\end{array}$ & & & & \\
\hline
\end{tabular}

REVERSIBILITY of Interfaces (lower triangle)

\begin{tabular}{r|l|} 
Effort 1 \\
Depth \\
\hline
\end{tabular}

Effort to reverse Depth in which interface is located

easy $1 \quad$ shallow 1

medium 2 medium 2

difficult $3 \quad$ deep 3
TRAILER 1

NATURE of Interfaces (upper triangle):

(adapted from Pimmler and Eppinger 1994)

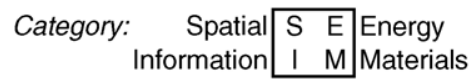

Intensity

Required 2

Desired 1

Indifferent 0

Undesired -1

Detrimental -2

\begin{tabular}{|r|}
\hline NUMBER of Interfaces \\
theoretical max 15 \\
theoretical min 5 \\
real 5 \\
\hline
\end{tabular}

TRAILER 2

NATURE of Interfaces (upper triangle): (adapted from Pimmler and Eppinger 1994)

\section{Category: Spatial S E Energy} Information 1 M Materials

Intensity

Required 2

Desired 1

Indifferent 0

Undesired -1

Detrimental -2

\begin{tabular}{|r|}
\hline NUMBER of Interfaces \\
theoretical max 15 \\
theoretical $\min 5$ \\
real 6 \\
\hline
\end{tabular}

Fig. 6. Interface matrices. 
duct into components, the interactions between these components are documented and coded in a matrix. Four forms of interactions can be considered according to Pimmer and Eppinger: (1) a spatial interaction identifies needs for adjacency or orientation between two elements, (2) an energy interaction identifies needs for energy transfer between two elements, (3) an information interaction identifies needs for information or signal exchange between two elements, and (4) a material interaction identifies needs for materials exchange between two elements. They further suggest specifying the importance and desirability, i.e., the intensity, of the interaction on a five-point scale from -2 to +2 . The identification and scoring of each interaction for each of the four forms results in a matrix that has in each interaction field four numbers between -2 and +2 . The upper left corner contains the number for the spatial-type interaction, the upper right the number for energy-type interactions, the lower left corner shows the number for information-type interactions, and the lower right corner displays the rating for material-type interactions. The upper triangles in Fig. 6 show the interface matrices for the two trailers. Empty cells can be interpreted as being filled with zeros. Due to their mechanical characteristics, most of the interfaces for both trailers are spatial in nature. The only exception is the energy and signal transmission from the towing vehicle to the rear lights. Note that despite their very different FCA schemes, both architectures exhibit a number of similarities with respect to the type of interfaces.

\subsubsection{Interface reversibility}

The second interface characteristic that needs to be analyzed is the interfaces' 'reversibility'. The notion of various product changes over the product life, such as upgrades, add-ons, adaptation, wear, consumption, or reuse - which are often assumed as being one of the major advantages of modular product architectures strongly depends on the reversibility of the interface.
The effort to reverse, or disconnect, the interface can serve as a proxy to determine the reversibility of an interface. This effort depends on two factors: first, the difficulty to physically disconnect the interface, and second, the interface's position in the overall product architecture.

Theoretically, every interface can be disconnected. However, that modular product architectures have strong interactions within modules and weak ones between them implies that the weakness of these relations can be translated into low efforts to reverse (or disconnect) the interface. The repair of an outer panel of an automobile door illustrates that the answer to this question lies on a continuum. Consider a conventional car door. The steel structure is welded together before it is painted jointly with the car's bodyin-white. In a final step, all trim parts are attached to the door. Now suppose the outer panel is damaged in an accident. To repair the outer panel all assembled parts would have to be removed, the damaged door outer panel would have to be cut, a new outer panel would have to be welded to the other door panels, the door would have to be repainted, and the components would have to be reassembled. Contrast this with a door architecture, where the outer panel is not part of the load carrying structure and not welded to it, but attached with a mechanism that is relatively easy to disconnect (e.g., screws). Not only can the door outer panel be replaced without first removing many other parts, the reversible attachment mechanism also reduces the level of skills and specialized equipment required to remove the damaged part and to attach the new one. Consequently, the overall effort to disconnect - or reverse - the interface between the outer panel and the rest of the door is lower for the alternative door architecture than for the conventional door architecture. This example demonstrates that the level of an interface's reversibility depends not only on its own technical specifications (skill and equipment requirements) but also on its position within the

Table 1

Criteria to assess effort level to disconnect interface

\begin{tabular}{llll}
\hline Score & 1 (low) & 2 (medium) & $3($ high) \\
\hline Tool requirements & None & Generic & Special \\
Time to disconnect (s) & $<10$ & $10-60$ & $>60$ \\
Examples & Snap-fit connection & Nut-bolt connection & Weld bond \\
\hline
\end{tabular}


Table 2

Criteria to assess depth level to disconnect interface

\begin{tabular}{lc}
\hline Score & $\begin{array}{l}\text { Fraction of total product components } \\
\text { that needs to be removed prior to the } \\
\text { interface disconnection }(\%)\end{array}$ \\
\hline 1 (low) & $<10$ \\
2 (medium) & $10-33$ \\
3 (high) & $>33$ \\
\hline
\end{tabular}

overall product, i.e., how deep it is 'buried' in the product. Similar efforts are to be expected for other product changes during product use, i.e., add-ons, upgrades, changes during the use phase, and replacement of worn or consumable components.

For the purpose of comparatively measuring the interfaces' reversibility, I suggest assigning two values to each interface. Note that others have suggested similar measures to assess disassembly efforts for recycling (e.g., Das et al., 2000). The first value represents the difficulty involved in disconnecting the interface. Its score corresponds to the time and tools required to disconnect the interface (Table 1). The second value represents the depth in which an interface is 'buried', how many other units have to be removed before a disconnection of the interface is possible. This score is specified in fractions of total number of components (on the hierarchy level under consideration) (Table 2). Both values should be assigned with the comparative purpose in mind.

The results for the two example trailers are shown in the lower triangles of the matrices in Fig. 6. With respect to the difficulty to reverse most of the interfaces, the two trailer concepts are very similar. For both product architectures, the difficulty can be considered to be relatively low, primarily because of the use of mechanical fasteners (only bed and hitch of trailer 1 are assumed to be welded together). Due to the relatively small number of components, none of the designs exhibit significant 'depth' in which some of the interfaces could be 'buried'. Note, however, that a component like the Upper Half of trailer 2 has an above average number of interfaces. If this component needed to be replaced, it would require disconnecting all relevant interfaces.

\subsubsection{Interface standardization}

The third interface category is concerned with the interfaces' roles regarding component substitutes and product families. This interface characteristic deserves particular consideration, because it is critical if one pursues product variety through component and interface standardization. A common idea about modular product architectures is the relative ease with which an inter-module interface is supposed to allow an exchange of sub-units. This 'ease' has two components. The first is the interface's reversibility (which was covered in the previous section), and the second is the degree to which there are alternatives for an exchange. The latter one is the subject of this section.

As discussed in the section on existing models, some researchers have used different types of component interchange to categorize different types of modularity. Component swapping, component sharing, fabricate-to-fit, bus, and sectional are often used characterizations (e.g., Kusiak, 1999; Pine, 1993; Ulrich and Tung, 1991). However, the extent to which an interface allows this interchangeability of components is a matter of the unit-of-analysis choice. For example, component swapping modularity and component sharing modularity do not describe the interface itself, but rather the alternatives that exist on either side of the interface. If one component is defined as the one remaining in the system (often the larger one) and the interface allows the exchange of the other one, then the term component swapping is used. On the other hand, if the larger one is exchanged (i.e., the reference switches to the smaller one) the term component sharing is used. Consider the interface between a lamp and a light bulb. If the light bulb is exchanged (say, with one with a different color) and the same lamp kept, it is called component swapping. If the same light bulb is used in a different lamp, however, it is called component sharing. Note that the technical characteristics of the interface can be identical in both cases. Thus, the use of these terms depends on which component is chosen as the reference system.

If the chosen reference system offers similar interfaces in various locations, the term bus modularity has been applied. Examples are electrical systems, shelving systems with rails and the bus systems used in computers. If the standardization is taken one step further, it allows the connection of every unit with every other unit. This is what is meant by sectional modularity. One example would be 
LEGO blocks, others include piping fittings or sectional sofas.

These examples illustrate two insights. First, they support the separate determination of functioncomponent allocation and interface characteristics that this framework introduces, because identical interfaces can be found in different functioncomponent allocation schemes, and a single function-component allocation scheme can exhibit multiple, different interface types. The features discussed in this section are characteristics of particular interfaces rather than the product architecture as a whole. Second, the extent to which an interface can be considered standardized from each component's perspective is key to assessing its role in a product family.

To identify the interfaces' role with respect to component interchangeability, I suggest a mapping tool that describes an interface from the perspectives of both components 'involved' in the interface (Fig. 7). One extreme, the lower left corner, indicates interfaces where there are very few alternatives to replace or substitute either one of the components (e.g., at a space station). The other extreme, the upper right corner, locates interfaces where multiple replacements or substitution options exist for both components (e.g., LEGO blocks). The map's center locates interfaces like the lamp/light bulb combination. A case of an interface where there are many alternatives for one component but very few for the other (upper left corner or lower right corner) can be imagined as a separate electrical system with a unique voltage (e.g., on a boat or at a remote house). The level of interface standardization increases from the lower left to the upper right corner of the map.

Fig. 7 shows the interfaces for the major functions of the two trailer examples. Each icon characterizes the alternatives on each side of an interface, separately one per function. Not knowing the product families that could surround these example trailers, it is assumed that the functions of trailer 1 exhibit a higher level of reusability across a product family than those of trailer 2. The reason for this is that it is more likely for those components that carry the functions to find use in other designs for trailer 1 than it is for trailer 2 , the latter showing a higher level of idiosyncrasy. However, the level of standardization is not homogenous across either product architecture. For exam- ple, while the component for trailer 2's function 'support cargo loads' is very unique, the components providing the function 'minimize air drag' can be viewed as also being usable for a similar but slightly different trailer, and the component corresponding to the function 'transfer loads to road' is exactly as standardized as the one of trailer 1.

\subsection{Pulling it all together: product architecture maps}

Together with the function-component allocation data, the interface information completes the description of the product architecture. Consequently, adding the information for all three interface dimensions to the function-component allocation map results in the product architecture map. These product architecture maps show in their $x-y$ plane how the functions are allocated to the components. Independent from that, and independent of each other, the different interface dimensions are shown along the vertical axis (z). These product architecture maps serve as a graphic representation of the complete product architecture description. They allow quick visual references of similarities and differences of the analyzed product architectures. Fig. 8 shows the maps for the two trailers. Note that for these pictorial representations, the measures for each of the three interface characteristics have been aggregated per function, if necessary.

The suggested product architecture assessment framework can serve as the nexus for creating the linkages between decisions in the domains of product, process, and supply chain. The next section provides an illustration of how the framework can be used to identify (a) the linkages themselves and (b) how to use this knowledge for trade-off analyses.

\section{Illustration}

To demonstrate how the product architecture coordinates decisions across product, process, and supply chain domains, a car door is introduced as an example product. The vast majority of today's car doors are constructed as a shell-shaped structure, welded together from stamped steel components (product architecture A in Fig. 9). 


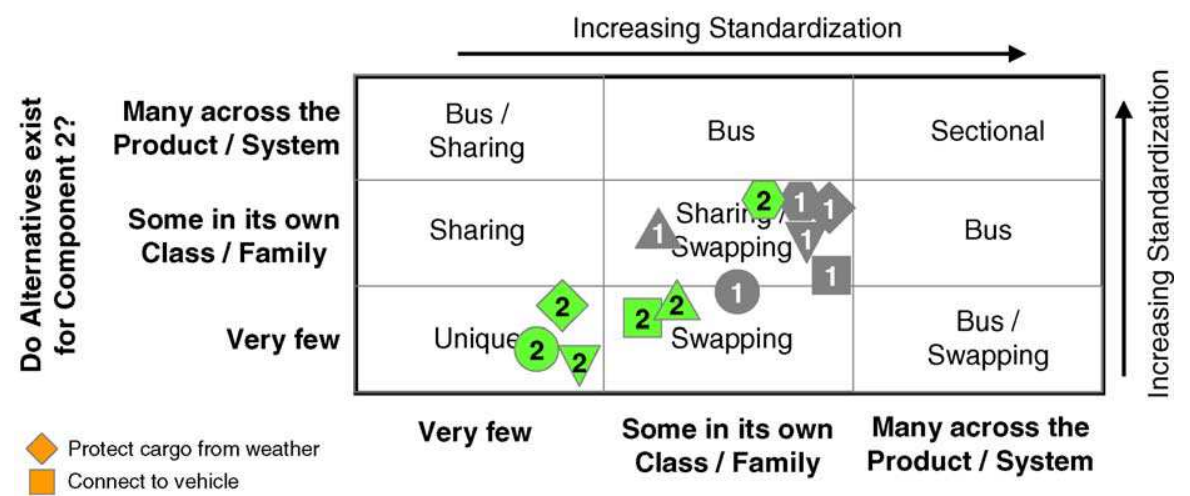

Do Alternatives exist for Component 1 ?

Fig. 7. Interface standardization.

The stamping manufacturing process requires expensive dedicated tooling (stamping dies). One possibility to reduce unit costs is to spread these fixed costs over larger production volumes. This is the underlying idea of strategies to use product platforms or common components. To be able to use a component across multiple products, however, requires that this component provides the functionality satisfactorily for each product of the product family. In the product architecture assessment framework, the function-component allocation style for a reused, i.e., common, component should ensure that the compo-

\section{Trailer 1}

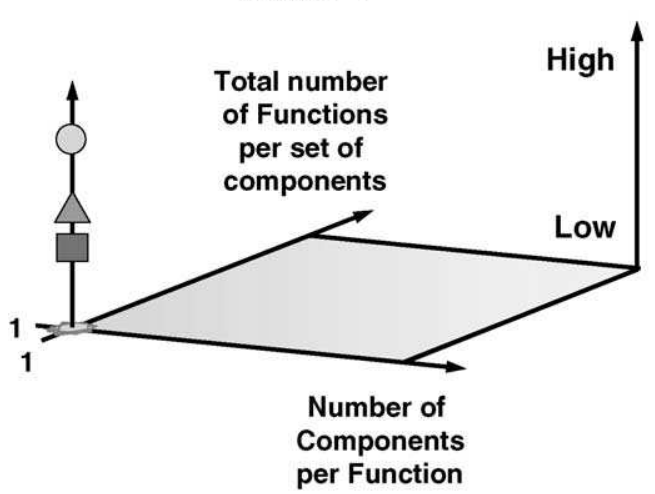

\section{Trailer 2}

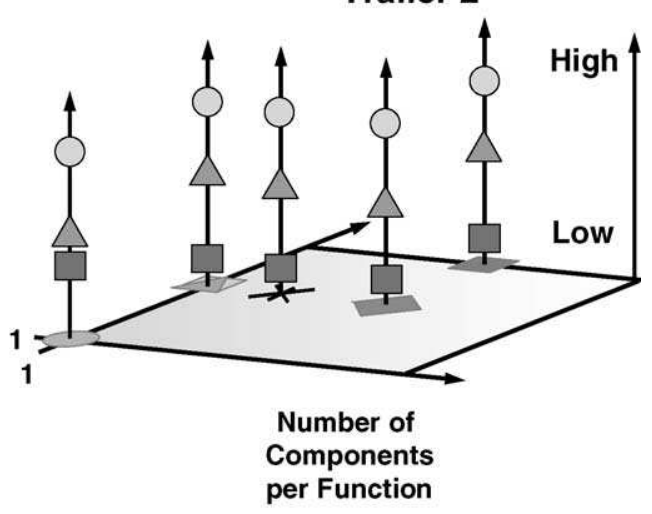

Interface characteristics (vertical):

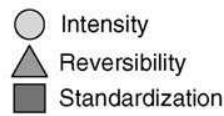

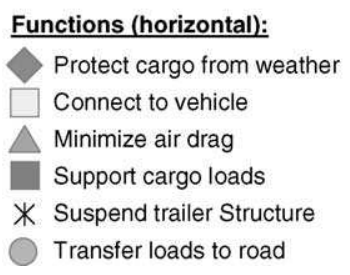

Fig. 8. Product architecture maps. 


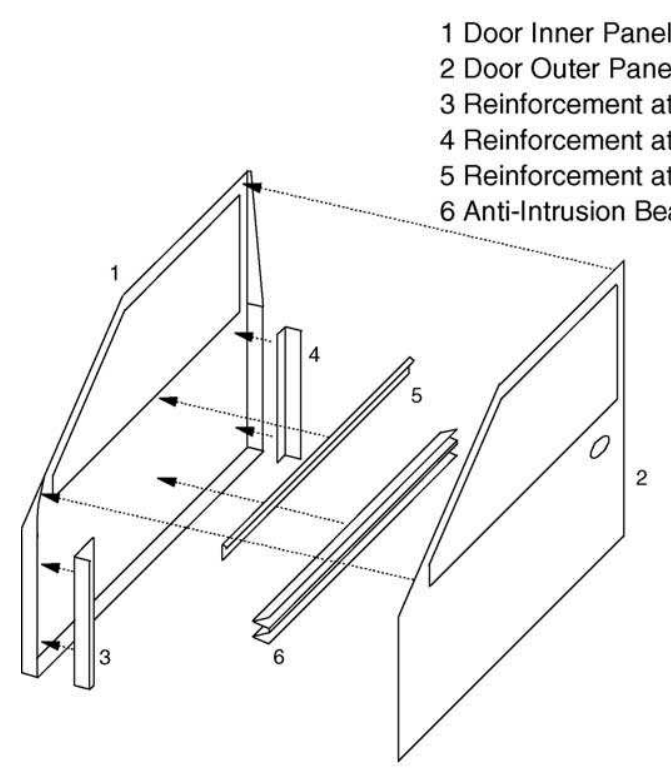

Product Architecture A
1 Door Outer Panel

2 Door Frame

3 Cruciform Outer

4 Cruciform Inner

5 Secondary Beam

6 Reinforcement

Fig. 9. Two automobile door structures with different product architectures.

nent provides the function under consideration as completely as possible, and is involved in additional functions as little as possible. Modular-like or integral-consolidated FCA styles are best for this purpose.

For the case of the car door, suppose the function 'structure' has been identified as a candidate to be common across a product family or multiple product generations. In case of product architecture A, the function 'structure' is located in the region of integralcomplex FCA styles. In contrast, product architecture B exhibits for the function 'structure' a FCA style more towards the left of the FCA plane (Fig. 10). Note that product architecture $\mathrm{B}$ is otherwise almost identical to product architecture A. It employs the same material (steel) and the same manufacturing technologies (stamping, welding) for its construction as product architecture $\mathrm{A}$, while exhibiting the same interface characteristics (Fig. 9). Note also that both door designs are based on real car doors. They are comparable in functionality and performance. For the conventional design numerous crash tests have demonstrated its safety performance. Doors with the design of product architecture B have not been mass produced yet, but crash tests with prototypes have demonstrated that it is comparable (if not superior) with regards to its safety performance (Townsend et al., 2001).

To illustrate how the product architecture, in this case the FCA style of the function 'structure', links decisions across domains, consider the implications of the use of common components in production for engineering analysis in product design. Using common components across product families (in this example, one could envision that the inner structure of the door, the cruciform, is used for similar related vehicle programs) requires the engineering analysis of this component to be extended to incorporate all possible applications for its multiple uses across the product family. In other words the number of constraints for designing this component has now been increased, making the design process more complicated. In a case of a car door structure for a sports car of a North American auto maker, this effect has caused a delay of several months with respect to the completion of the design work. Fig. 11 illustrates how the decisions for common parts in production on one hand and higher levels of complexity in product development on the other are linked through the product architecture. 


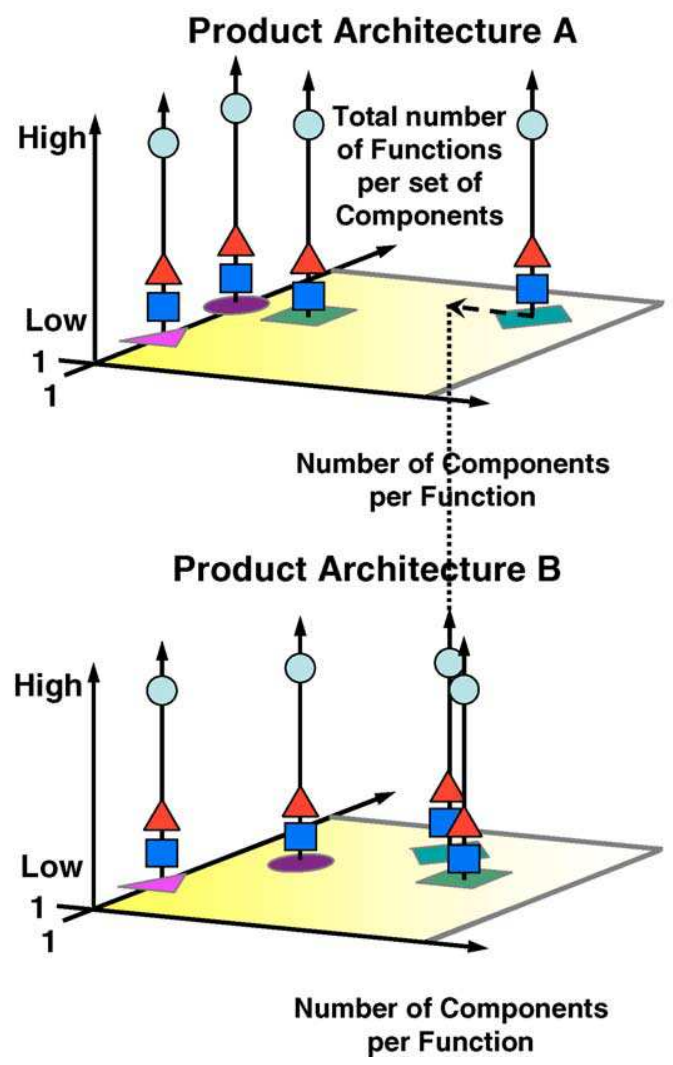

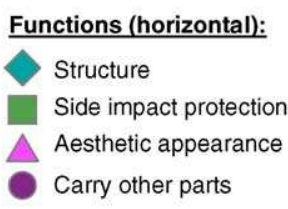

Interface characteristics (vertical):

Intensity

Reversibility

Standardization

Fig. 10. Product architecture change in the FCA scheme.

The door architecture B also illustrates a second case of decision coordination across domains via the product architecture. A postponement (or late customization) strategy in a supply chain requires moving the point at which a product becomes unique as much as possible towards the end of the supply chain, i.e., towards the customer. Suppose the car door is now offered in multiple colors. Color is represented by the function (or attribute) 'aesthetic appearance'. This function is provided by the door outer panel. Ideally, one would want to keep the outer panel and the rest of the door separate to ensure pooling effects for the common components. The welding manufacturing process, however, has to be applied prior to painting for it otherwise destroys the paint. If, however, a different joining technology between the color providing component and the rest of the product is used, e.g., a mechanical fastener, then the process sequence could be reversed and the differentiation point could be moved towards the customer. The change from a welded connection to one using mechanical fasteners is captured by the product architecture characteristic 'interface reversibility' of the function 'aesthetic appearance' (Fig. 12). While this change in interface reversibility makes the reversal of operational sequences for the supply chain possible, it also signals a change in the assembly processes used in the manufacturing process domain. Fig. 13 illustrates the coordinating role of the product architecture for this example.

The situations in both of these example cases require coordinating the decisions across the domains. Trade-off analyses that compare, for example, the cost savings through component commonality with longer product development times or that compare risk pooling in the supply chain with the additional cost for a more expensive joining mechanism can help to identify solutions that are optimal across the entire supply chain. The product architecture serves as the connection point for these trade-off analyses, and the 


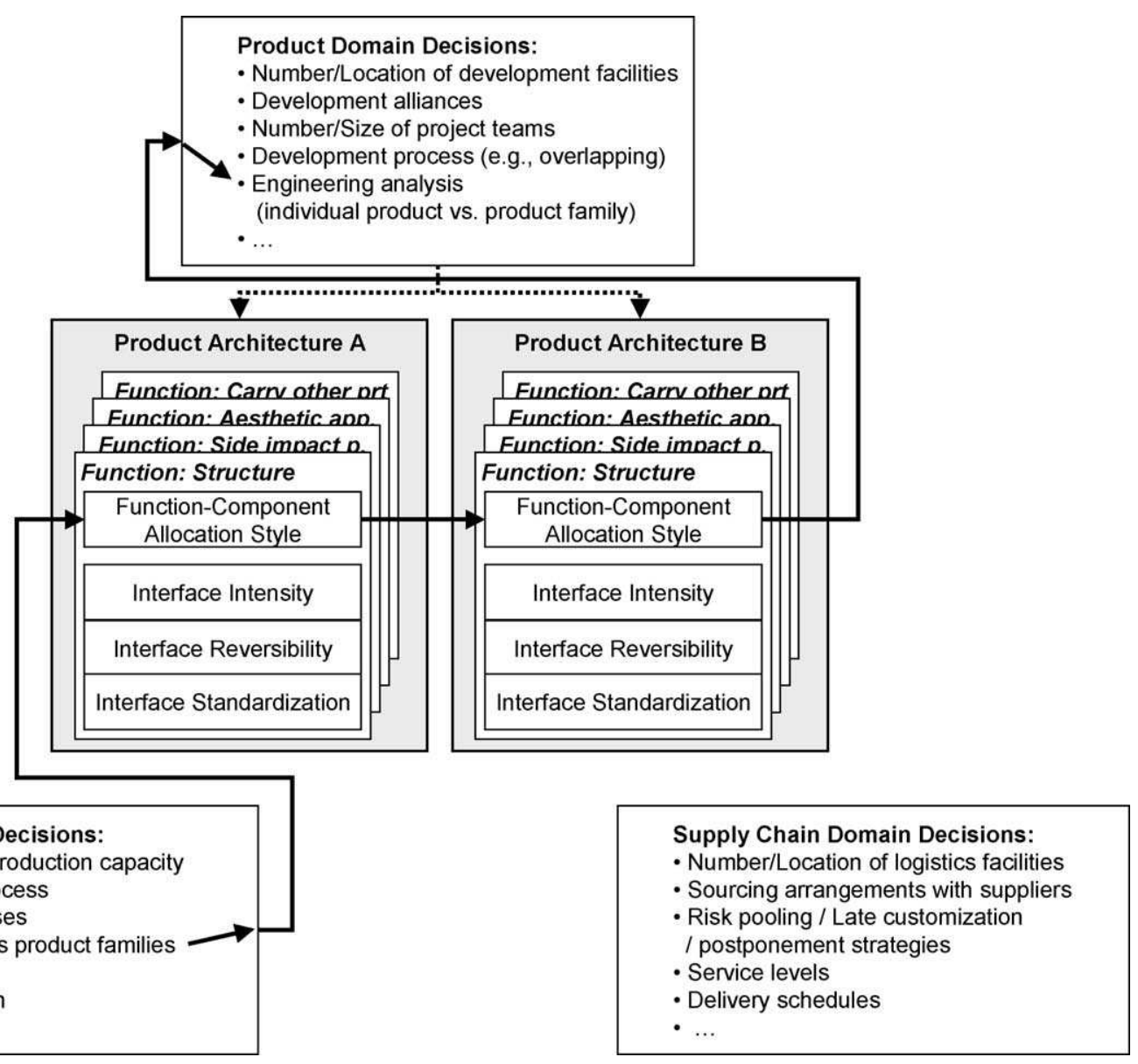

Fig. 11. Product architecture coordinates design decisions across process and product domains.

product architecture assessment methodology presents a structure to which cost models and similar tools can be connected (Fixson, 2004).

\section{Conclusion and future research}

Many of today's companies are operating in market environments in which customer populations are becoming more heterogeneous and product life cycles are steadily shortening. Higher levels of demand variety and less time to get it right increase the weight of decisions made early in the product development process on the success or failure of a product. Ideally, one would want to make the consequences of these early design decisions on all steps in the value chain visible. A central element for such an approach is a comprehensive operationalization of the product architecture concept. In this paper I provide such an operationalization by developing a multi-dimensional descriptive product architecture framework. This framework integrates insights from literature streams on new product development, operations management, and supply chain management. This framework can serve multiple purposes in management and research.

Managers can apply the product architecture framework in three ways. First, they can use it as a guideline to focus on design decisions critical for the product and company under consideration. For a planned product and operation strategy, it can help to identify those architectural characteristics that need to 


\section{Product Architecture B}

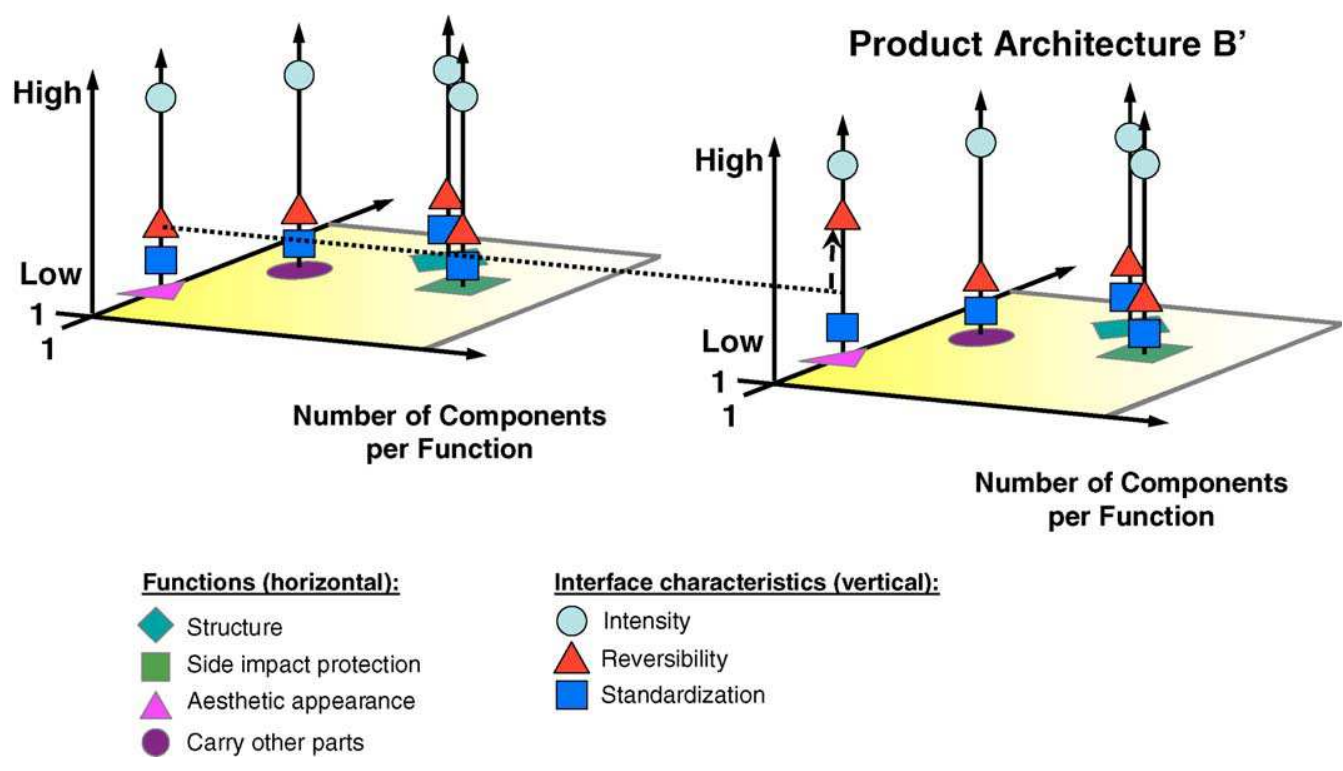

Fig. 12. Product architecture change in interface reversibility.

be focused on during early product design to best serve that strategy. The second way in which the product architecture framework can help constitutes the reverse situation. It can help to explore the advantages and limitations of various operational strategies for given product architectures. For example, in conjunction with other evaluation tools (e.g., cost analyses), the framework can help to make the price visible that is to be paid for selected operational strategies while using certain product architectures. Third, the framework can help to improve a company's strategy planning capabilities over time. Using the framework in one or both of the ways described above will help to develop a deeper understanding about the ways in which product architecture choices are linked to many decisions across the domains of product, process and supply chain. With help of scenarios the possibilities and limits of different product architectures could be explored.

While the product architecture framework produces promising results in the research realm, the work is in its early stages, and more research remains to be done. Three major avenues for future research can be identified. First, more data points could help test the product architecture framework, both con- cerning the detected differences in product architecture and concerning their linkages across the domains of product, process, and supply chain. Such studies could compare products within and across industries, or tie them to performance measures of interest, i.e., cost, revenues, time, quality, etc.

Second, as the examples have illustrated, some architectural features are beneficial for some process's performance but can create penalties for the performance of another, e.g., inventory savings vs. additional manufacturing costs. It is very likely that some of the cross-domain effects involve more than two decisions. Moving towards a more holistic view of the entire value chain will require trade-off models capable of dealing with higher levels of complexity.

Third, the framework could be applied to study product architecture change over time. Successive generations of a product could be described and measured to investigate whether there are patterns in which product architectures evolve. It has been claimed that many products are becoming increasingly modular. I conjecture that the real picture is more complicated. There are multiple forces working simultaneously (improvements in product technology and manufacturing processes, ratio of provided to 


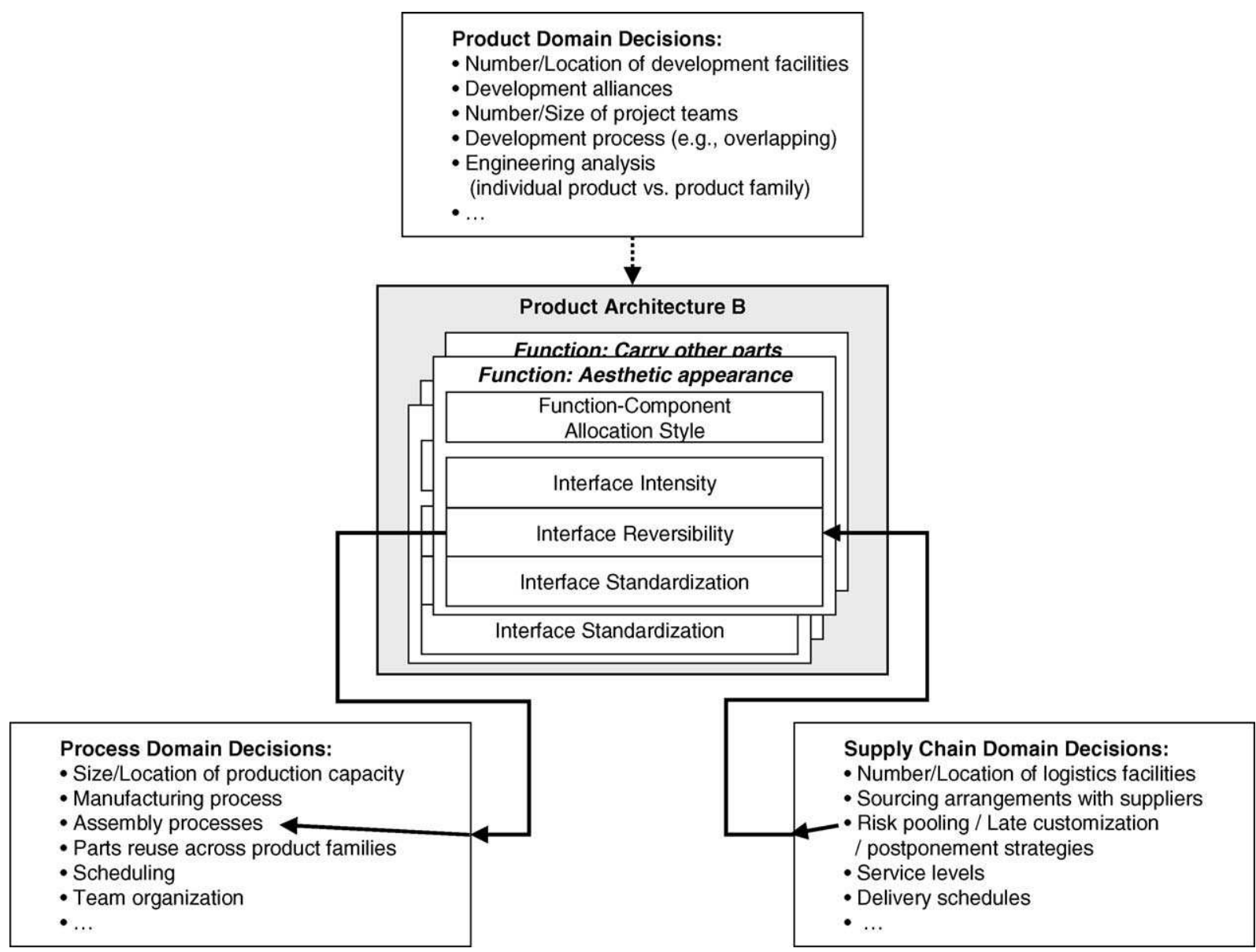

Fig. 13. Product architecture coordinating decisions across supply chain and process domains.

requested product performance, increasing interconnection between formerly distinct products, etc.) and the resulting direction of the product architecture appears not necessarily to be always more modular. The framework presented in this paper could help to uncover some of the ways in which product architectures change over time.

\section{Acknowledgements}

I would like to thank three anonymous reviewers and the editors of this special issue for their insightful and constructive comments on earlier versions of this paper. Research support from the International Motor Vehicle Program at MIT is gratefully acknowledged.

\section{References}

Ahmadi, R., Roemer, T.A., Wang, R.H., 2001. Structuring product development processes. European Journal of Operational Research 130, 539-558.

Alexander, C., 1964. Notes on the Synthesis of Form. Harvard University Press, Cambridge, MA.

Allen, K.R., Carlson-Skalak, S., 1998. Defining product architecture during conceptual design. ASME Design Engineering Technical Conference, ASME, Atlanta, GA.

Baiman, S., Fischer, P.E., Rajan, M.V., 2001. Performance measurement and design in supply chains. Management Science 47 (1), 173-188.

Baker, K.R., Magazine, M.J., Nuttle, H.L.W., 1986. The effect of commonality on safety stock in a simple inventory model. Management Science 32 (8), 983-988.

Baldwin, C.Y., Clark, K.B., 2000. Design Rules. Volume 1: The Power of Modularity. MIT Press, Cambridge, MA. 
Banker, R.D., Datar, S.M., Kekre, S., Mukhopadhyay, T., 1990. Cost of product and process complexity. In: Kaplan, R.S. (Ed.), Measures for Manufacturing Excellence. Harvard Business School Press, Boston, MA, pp. 269-290.

Boer, M., Logendran, R., 1999. A methodology for quantifying the effects of product development on cost and time. IIE Transactions 31 (4), 365-378.

Boothroyd, G., Dewhurst, P., Knight, W.A., 2002. Product Design for Manufacture and Assembly. Marcel Dekker, New York.

Brown, S.L., Eisenhardt, K.M., 1995. Product development: past research, present findings, and future directions. Academy of Management Review 20 (2), 343-378.

Browning, T.R., 2001. Applying the design structure matrix to system decomposition and integration problems: a review and new directions. IEEE Transactions on Engineering Management 48 (3), 292-306.

Chesbrough, H.W., Kusunoki, K., 1999. The modularity trap: innovation, technology phase shifts, and the resulting limits of virtual organizations. In: Nonaka, I., Teece, D.J. (Eds.), Managing Industrial Knowledge-Creation, Transfer and Utilization. SAGE Publications, London, pp. 202-230.

Christensen, C.M., 1992. Exploring the limits of the technology Scurve. Part I: Component technologies. Production and Operations Management 1 (4), 334-357.

Clark, K.B., Fujimoto, T., 1991. Product Development Performance. Harvard Business School Press, Boston, MA.

Collier, D.A., 1982. Aggregate safety stock levels and component part commonality. Management Science 28 (11), 1297-1303.

Das, S.K., Yedlarajiah, P., Narendra, R., 2000. An approach for estimating the end-of-life product disassembly effort and cost. International Journal of Production Research 38 (3), 657-673.

Desai, P., Kekre, S., Radhakrishnan, S., Srinivasan, K., 2001. Product differentiation and commonality in design: balancing revenues and cost drivers. Management Science 47 (1), 37-51.

Doran, D., 2003. Supply chain implications of modularization. International Journal of Operations \& Production Management 23 (3), 316-326.

Duray, R., Ward, P.T., Milligan, G.W., Berry, W.L., 2000. Approaches to mass customization: configurations and empirical validation. Journal of Operations Management 18, 605625.

Eppinger, S.D., Whitney, D.E., Smith, R.P., Gebala, D.A., 1994. A model-based method for organizing tasks in product development. Research in Engineering Design 6, 1-13.

Feitzinger, E., Lee, H.L., 1997. Mass customization at HewlettPackard: the power of postponement. Harvard Business Review $75,116-121$.

Fine, C.H., 1998. Clockspeed-Winning Industry Control in the Age of Temporary Advantage. Perseus Books, Reading, MA.

Fixson, S.K., 2003. The multiple faces of modularity-a literature analysis of a product concept for assembled hardware products. Technical Report 03-05. Industrial \& Operations Engineering, University of Michigan, Ann Arbor, MI, p. 87.

Fixson, S.K., 2004. Assessing product architecture costing: product life cycles, allocation rules, and cost models. ASME 2004 Design Engineering Technical Conferences, ASME, Salt Lake City, UT.
Fleischer, M., Liker, J.K., 1997. Concurrent Engineering Effectiveness-Integrating Product Development Across Organizations. Hanser Gardner Publications, Cincinatti.

Garg, A., 1999. An application of designing products and processes for supply chain management. IIE Transactions 31 (5), 417-429.

Garud, R., Kumaraswamy, A., 1996. Technological designs for retention and reuse. International Journal of Technology Management 11 (7/8), 883-891 (special issue).

Gerchak, Y., Magazine, M.J., Gamble, A.B., 1988. Component commonality with service level requirements. Management Science 34 (6), 753-760.

Griffin, A., 1997. Modeling and measuring product development cycle time across industries. Journal of Engineering and Technology Management 14, 1-24.

Gulati, R.K., Eppinger, S.D., 1996. The coupling of product architecture and organizational structure decisions. Working Paper \#3906-96. MIT Sloan School of Management, Cambridge, MA, p. 31.

Haddad, C.J., 1996. Operationalizing the concept of concurrent engineering: a case study from the US auto industry. IEEE Transactions on Engineering Management 43 (2), 124-132.

Henderson, R.M., Clark, K.B., 1990. Architectural innovation: the reconfiguration of existing product technologies and the failure of established firms. Administrative Science Quarterly 35, 9-30.

Huang, C.-C., Kusiak, A., 1998. Modularity in design of products and systems. IEEE Transactions on Systems, Man and Cybernetics A: Systems and Humans 28 (1), 66-77.

Jiao, R.J., Huang, G.G.Q., Tseng, M.M., 2004. Concurrent enterprising for mass customization. Concurrent Engineering: Research and Application 12 (2), 83-88.

Kaski, T., Heikkila, J., 2002. Measuring product structures to improve demand-supply chain efficiency. International Journal of Technology Management 23 (6), 578-598.

Kota, S., Sethuraman, K., Miller, R., 2000. A metric for evaluating design commonality in product families. Journal of Mechanical Design 122 (4), 403-410.

Koufteros, X., Vonderembse, M.A., Doll, W., 2001. Concurrent engineering and its consequences. Journal of Operations Management 19, 97-115.

Krishnan, V., Gupta, S., 2001. Appropriateness and impact of platform-based product development. Management Science 47 (1), 52-68.

Kusiak, A., 1999. Engineering Design: Products, Processes, and Systems. Academic Press, San Diego.

Langlois, R.N., Robertson, P.L., 1992. Network and innovation in a modular system: Lessons from the microcomputer and stereo component industries. Research Policy 21, 297-313.

Lee, H.L., Tang, C.S., 1998. Variability reduction through operations reversal. Management Science 44 (2), 162-172.

Loch, C.H., Mihm, J., Huchzermeier, A., 2003. Concurrent engineering and design oscillations in complex engineering projects. Concurrent Engineering: Research and Application 11 (3), 187199.

Magretta, J., 1998. The power of virtual integration: an interview with dell computer's Michael Dell. Harvard Business Review $76,73-84$. 
Martin, M.V., Ishii, K., 2002. Design for variety: developing standardized and modularized product platform architectures. Research in Engineering Design 13, 213-235.

Meyer, M.H., Lehnerd, A.P., 1997. The Power of Product Platforms. The Free Press, New York.

Mirapaul, M., 2001. Made especially for you-in industrial quantities. The New York Times, New York, NY, March 11, p. 11.

Momme, J., Moeller, M.M., Hvolby, H.-H., 2000. Linking modular product architecture to the strategic sourcing process: case studies of two Danish industrial enterprises. International Journal of Logistics: Research and Applications 3 (2), 127146.

Nevins, J.L., Whitney, D.E., 1989. Concurrent Design of Products and Processes: A Strategy for the Next Generation in Manufacturing. McGraw-Hill, New York.

Newcomb, P.J., Bras, B., Rosen, D.W., 1998. Implications of modularity on product design for the life cycle. Journal of Mechanical Design 120 (3), 483-491.

Nobeoka, K., Cusumano, M.A., 1995. Multiproject strategy, design transfer, and project performance: a survey of automobile development projects in the US and Japan. IEEE Transactions on Engineering Management 42 (4), 397-409.

Pahl, G., Beitz, W., 1996. Engineering Design-A Systematic Approach. Springer, London.

Pimmler, T.U., Eppinger, S.D., 1994. Integration analysis of product decompositions. Working Paper \# 3690-94-MS. MIT Sloan School of Management, Cambridge, MA, p. 39.

Pine, B.J.I., 1993. Mass Customization. Harvard Business School Press, Boston, MA.

Reinertsen, D.G., 1997. Managing the Design Factory. The Free Press, New York.

Roemer, T.A., Ahmadi, R., Wang, R.H., 2000. Time-cost trade-offs in overlapped product development. Operations Research 48 (6), $858-865$.

Rusinko, C.A., 1999. Exploring the use of design-manufacturing integration (DMI) to facilitate product development: a test of some practices. IEEE Transactions on Engineering Management 46 (1), 56-71.

Salvador, F., Forza, C., Rungtusanatham, M., 2002. Modularity, product variety, production volume, and component sourcing: theorizing beyond generic prescriptions. Journal of Operations Management 20, 549-575.

Sanchez, R., Mahoney, J.T., 1996. Modularity, flexibility, and knowledge management in product and organization design. Strategic Management Journal 17, 63-76 (winter special issue).

Schilling, M.A., 2000. Towards a general modular systems theory and its application to interfirm product modularity. Academy of Management Review 25 (2), 312-334.

Simon, H.A., 1962. The architecture of complexity. Proceedings of the American Philosophical Society 106 (6), 467-482.
Simpson, T.W., 2003. Product platform design and optimization: status and promise. ASME 2003 Design Engineering Technical Conferences, ASME, Chicago, IL.

Sosa, M.E., Eppinger, S.D., Rowles, C.M., 2003. Identifying modular and integrative systems and their impact on design team interactions. Journal of Mechanical Design 125, 240-252.

Steward, D.V., 1981. System Analysis and Management: Structure, Strategy, and Design. Petrocelli Books, New York/Princeton.

Terwiesch, C., Loch, C.H., De Meyer, A., 2002. Exchanging preliminary information in concurrent engineering: alternative coordination strategies. Organization Science 13 (4), 402-419.

The Economist Intelligence Unit, 2000a. Developments in the global sports car sector. EIU Motor Business International, pp. 43-69.

The Economist Intelligence Unit, 2000b. Global niche vehicle markets: prospects to 2005. EIU Motor Business Journal, pp. $150-164$.

Thomke, S.H., 1997. The role of flexibility in the development of new products: an empirical study. Research Policy 26, 105-119.

Thonemann, U.W., Brandeau, M.L., 2000. Optimal commonality in component design. Operations Research 48 (1), 1-19.

Townsend, J., Kaczmar, M., El-Sayed, M., 2001. Modular door system for side impact safety of motor vehicles. In: Proceedings of the 17th International Technical Conference on the Enhanced Safety of Vehicles (ESV), Amsterdam, The Netherlands.

Tu, Q., Vonderembse, M.A., Ragu-Nathan, T.S., Ragu-Nathan, B., 2004. Measuring modularity-based manufacturing practices and their impact on mass customization capability: a customerdriven perspective. Decision Sciences 35 (2), 147-168.

Ulrich, K.T., 1995. The role of product architecture in the manufacturing firm. Research Policy 24, 419-440.

Ulrich, K.T., Eppinger, S.D., 2000. Product Design and Development. McGraw-Hill, Boston.

Ulrich, K.T., Pearson, S.A., 1998. Assessing the importance of design through product archaeology. Management Science 44 (3), 352-369.

Ulrich, K.T., Tung, K., 1991. Fundamentals of product modularity. Working Paper WP\# 3335-91-MSA. MIT Sloan School of Management, Cambridge, MA, p. 14.

van Hoek, R.I., Weken, H.A.M., 1998. The impact of modular production on the dynamics of supply chains. The International Journal of Logistics Management 9 (2), 35-50.

von Hippel, E., 1990. Task partitioning: an innovation process variable. Research Policy 19 (5), 407-418.

Whitney, D.E., 1988. Manufacturing design. Harvard Business Review 66, 83-91.

Worren, N., Moore, K., Cardona, P., 2002. Modularity, strategic flexibility, and firm performance: a study of the home appliance industry. Strategic Management Journal 23, 1123-1140.

Yassine, A.A., Joglekar, N.R., Braha, D., Eppinger, S.D., Whitney, D.E., 2003. Information hiding in product development: the design churn effect. Research in Engineering Design 14, 145161. 